\title{
Virtual Tours to Promote the Remote Customer Experience
}

\author{
Sara CAVALLARO ${ }^{\mathrm{a}}$, Fabio GRANDI ${ }^{\mathrm{a}}$, Margherita PERUZZINI ${ }^{\mathrm{a}, 1}$, Francesca DE \\ $\mathrm{CANIO}^{\mathrm{b}}$ \\ a Department of Engineering "Enzo Ferrari”, University of Modena and Reggio \\ Emilia, Modena, Italy \\ b Department of Economy "Marco Biagi”, University of Modena and Reggio Emilia, \\ Modena, Italy
}

\begin{abstract}
Today, virtual reality and augmented reality can allow people to interact with products and places in a very realistic way. In this direction, the use of immersive virtual tours (VTs) can improve the users' experience, their perceptions, attitudes and even intended behaviours as potential or actual consumers. The paper focuses on a traditional Italian cheese product and defines a transdisciplinary, multimodal approach where VT helps the remote customer experience based on a VT application to virtually visit a Parmigiano Reggiano cheese dairy, using cuttingedge virtual reality set-up. The paper describes how to create a virtual tour of industrial plants by mapping the main actions, from the storytelling definition, to the plant digitization, until the creation of the virtual, immersive and multimodal application using Unity3D. The VT combines visual experience with gesture recognition and audio stimulation, adding also olfactory cues, in order to create an interactive and realistic experience.
\end{abstract}

Keywords. Virtual Reality, Virtual Tours, Customer Experience, user-centered design, multimodal approach

\section{Introduction}

Virtual Reality (VR) technologies are able to create interactive, digital environments to give users the illusion of displacement to another location, also simulating different tasks [1]. To achieve this result, a set of technologies (e.g. head-mounted display, input devices, motion capture) are used to interact with an artificial scenario, digitally simulated with a high-performance computer, reproducing a real world or creating an imaginary environment. Nowadays, VR applications are increasingly widespread due to the reduced cost of devices and the development of robust platforms that can limit the programming effort [2]. VR applications can range from design to manufacturing, comfort assessment and training, from medicine [3] to industry [4], museum [5] and marketing [6]. However, even though VR promises to be validly used for consumer marketing, its potential impacts are currently not well understood [7]. In particular, the combination of $\mathrm{VR}$ and $360^{\circ}$ videos to create some novel marketing experiences has not been exploited in a meaningful way yet [8], although is actually not exploited. Moreover, the Covid-19 pandemic situation emphasized the need of new marketing solutions in

\footnotetext{
${ }^{1}$ Corresponding Author, Mail: margherita.peruzzini@unimore.it.
} 
order to promote remote experience of products and places. In the last year, VR offered a risk-free way to escape the destination and travel in a safe and comfortable way [9]. In this context, VR could be used to ensure the creation of an interactive and engaging tours with the scope to emotionally affect the user and raise his/her awareness about the culture of a typical product and its origin, encouraging consumers from all over the world to visit physical dairies and to buy products. Companies can share with their customers an immersive, realistic experience with the product and the production process. From literature review, it emerged that VTs are already used for retail purposes, mainly based on 360 images and videos [10], but customers are barely involved in the process of production to raise their interest in the product. The aim of the research is using VR to replicate the customer experience lived by users inside the production site, choosing one of the main Italian well-known agri-food products, the Parmigiano Reggiano (PR) cheese. The adopted approach was defined transdisciplinary as it integrated computer sciences, engineering disciplines and user-centered design approach together with marketing issues, dissolving the boundaries between them, and promoting learning-bydoing. It was possible by applying technical virtual simulations with a novel marketing scope. This work describes how to use VTs to create a remote customer experience and validate this approach on the mentioned case.

\section{Research background}

In recent decades, the ever-increasing technological innovation, the world interconnection and the lower cost of technological devices have grown a strong motivation towards the digital world, especially in the retail context [11]. The application of immersive virtual technologies is aimed at supporting experience simulation, as well as training [12], in a variety of different application areas, ranging from therapy [13], marketing [14,15], gaming [16], film industries [17], education [18,19], art and museums [20], sales al retail [21], tourism [22], until to wine tourism gastronomic [23]. VR tools are able to digitally reconstruct the real world, including spaces and objects, that can be explored through appropriate devices, interacting with production sites and products. Focusing on the marketing sector, virtual simulation can lead a consequently positive impact on the user's purchasing decisions by showing remotely the product and/or production process features [24]. For instance, companies can give an immersive virtual tour to potential customers, able to simulate an actual interaction with the product and the production site even from considerable distances, practically all over the world.

Moreover, the last pandemic scenario due to COVID-19 accelerated the need to create VTs as a real opportunity to effectively bring people in places they cannot visit. Indeed, VTs can easily give access to a specific location in a remote way $[25,26]$, a museum [27], a process or a product production for marketing purposes [28] or a specific tourist attraction [29,30]. In addition, VTs could be also used for educational scopes, for students' learning [31] or tourists' education [19]. The majority of VTs are "static" considering the user in a fixed position viewing a $360^{\circ}$ image [32] or experiencing an engaging $360^{\circ}$ video [33]. On the contrary, a VT is more immersive and interactive, and enables the user to freely move into the scene, being involved in specific tasks thanks to a responsive scenario. 


\section{Methodology}

This paper proposes a methodology to effectively build interactive VTs to empower local products marketing and sales. For this purpose, the new proposed methodology aims at creating a remote customer experience with the final goal to improve the number of people visiting the production site and improve the product sales, also in different geographical areas, using a user-centered approach, starting from the user research and user needs' definition. The method uses several VR technologies to create an interactive simulation by combining $360^{\circ}$ videos with interactive virtual scenes to stimulate the users' multi-sensorial involvement and provide a valuable customer experience in a remote way.

The methodology exploits a set of software and hardware devices as shown in Figure 1. First of all, Unity3D is the main development platform for generating virtual and immersive contents to create a true-to-life simulation. Moreover, a specific VR platform (SteamVR) is used to enjoy the VR space wearing a head mounted display (HMD), managing specific camera settings to adjust the correct user's point of view. Video editing software tools (Insta360 Studio 2020 and Premiere Pro) are used for video recording and post-processing. In addition, Blender is adopted for 3D modelling and high-quality rendering. Finally, Reaper was useful for audio editing and recording correction about the audio storytelling by the narrative voice.

Software tools:

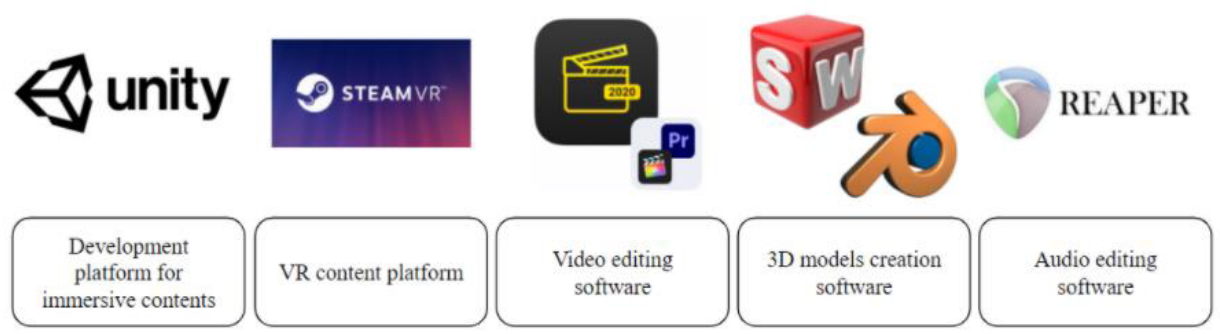

Hardware tools:
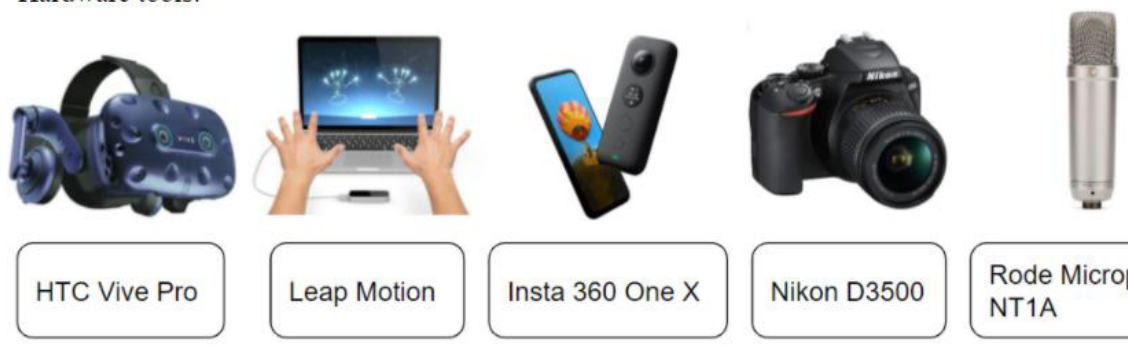

Rode Microphone NT1A

Figure 1. Adopted software and hardware tools.

About hardware devices, the HTC Vive pro eye is used as HMD; it is equipped with 32 infrared sensors for 360-degree tracking, a gyroscope, an accelerometer, and a laser position sensor. The Leap Motion controller allowed hand tracking and gesture recognition to make users interact with its bare hands. Hands position, even the fingers, are tracked with high-precision infrared camera system and digitalized by complex 
mathematical algorithms. For shooting immersive contents and digitizing real sites, a 360 camera (Insta 360 One X) is used together; a reflex camera (Nikon D3500) is used then for texture gathering. A smartphone is adopted for the One X camera remote control, for streaming in real time the camera point of view and light-effect settings. At last, a high-quality recorder (Roe Microphone NT1A) is used for audio recording.

Using the proposed set-up, five phases are defined to create a VT simulation as shown in Figure 2, according to a user-centered approach.

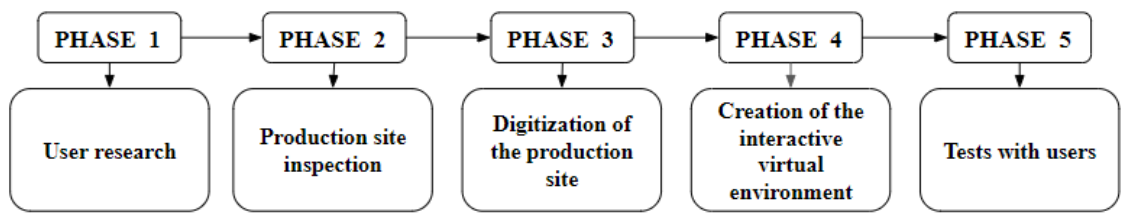

Figure 2. Step by step methodology.

The first step for the VT creation is the User research. It allows analysing the main consumer users, understanding their habits, needs and motivations. A sample of potential customers is usually interviewed and asked to fill a questionnaire to define their profile. In order to achieve this target, personas could be an effective way to define different profiles. Personas are 'fictitious, specific, concrete representations of target users' [34]. The personas are investigated during the pre-work studying. The answer is: What are the potential clients to whom it may concern?

The second phase is the Production site inspection. After visiting different production sites, we choose the best location for video shooting. After that, the production process is analysed in order to identify the main steps and narrated by marketing-oriented storytelling [35]. During the inspection, we need also define the type of digitalization to apply, between a) capturing the physical scenario with a digital $360^{\circ}$ camera, or b) digitally creating the scenario by CAD models and materials with real textures. The choice mainly depends on specific location characteristics and level of interaction of the final VT. The advantage of recording $360^{\circ}$ videos is high-fidelity with the real production site, while 3D model reconstruction permits user's interaction with objects.

After that, the Digitization of the production site is realized by both $360^{\circ}$ video recording and 3D CAD models creation, as decided in the previous phase. In the former case, the main challenges are: positioning the camera in the best place (avoiding principal character in stitching area, the fish-eye effect, and keeping a certain distance from walls, people, and objects), and controlling video framing to capture every detail throughout the surrounding space. If objects require a high-level of detail, it is desirable to use a specific software in order to reproduce the true-to-life textures in the virtual environment. Subsequently, the attention is dedicated to the Creation of the virtual interactive environment. VR devices must be firstly settled and integrated, depending of the VT creation needs. The stereoscopic reproduction of $360^{\circ}$ videos need to map the video into a sphere to project the recording in the virtual world, while the creation of interactive scenes starts modelling the virtual scenario, represented by walls, ceiling, ground and setting of light condition, and importing 3D models of virtual objects. Moreover, objects' behaviours must be settled to create the desired interaction with users. Usually, also audio feedback must be added for a realistic experience. All scenes are then grouped within a customized script to allow the user to navigate the VT. 
Finally, Tests with users are organized to validate the VT effectiveness and impressions. It is based on the analysis of the users' subjective impression and behaviours during the virtual experience. Users are asked to compile a pre-test questionnaire about demographic data, familiarity and level of expertise with VR tools, and knowledge on the specific product. After testing, users are asked to compile a post-test questionnaire about personal judgement and impressions about the quality of the experience during the VT simulation (e.g. engagement, easy to use, level of interest, sickness).

\section{Case study}

The case study refers to the visit to a dairy of a typical Italian product, the Parmigiano Reggiano cheese. The main scope is creating an immersive and interactive VT able to make users experiencing the main phases of cheese production and recreate the most relevant sensory aspects in a remote way. In this way, the virtual visit can be offered to a huge variety of potential customers who cannot physically go to the specific territory. It will open main opportunities for the producing companies to extend their market reaching a wider public with respect to the current physical visits.

Phase 1 focused on user research and aimed at understanding the target users and defining their features. Several personas were defined in the research; an example is represented in Figure 3.

Phase 2, about the production site inspection, involved different production sites in the Emilian territory, more specifically in the Modena area. Among all dairies, the "4 Madonne" cheese factory was chosen for video shooting (https://www.caseificio4madonne.it/). Different areas inside the dairy were selected, representing the main steps of the production process. A storytelling was defined as described in Figure 4.

Phase 3 was about the digitization of physical scenarios, using the Unity3D platform. The VT was structured in five different scenes, properly linked one after the other, as follows:

1. Welcome virtual scenario;

2. 360-videos of the entire PR production (from milk preparation to ageing);

3. Beating virtual scenario;

4. Fire branding virtual scenario;

5. Virtual tasting.

The first scene reproduces an entrance hall, in which the visitor meets the avatar (in this case, a dairyman) that guides him during the VT and provides useful information about the production process. When the simulation starts, an avatar tour guide begins to narrate the product origins. Different information panels were introduced in the scene in order to enrich the experience of the visitor: a territory map showing the cheese production area, infographic about the production process, and an interactive panel to listen to additional information by pushing one of the panel buttons like in a tablet interface (e.g. in-depth history, biodiversity, territory, consortium, counterfeiting, list of dairies).

In the second scene, 360-videos of the real production process were edited and mounted in order to highlight the main phases of production, paying attention to avoid image distortion and stitching issues. To increase the level of immersion, the narrating voice is balanced with the environmental noise of the production area. In this case, the scene is automatically changed at the end of the videos. 


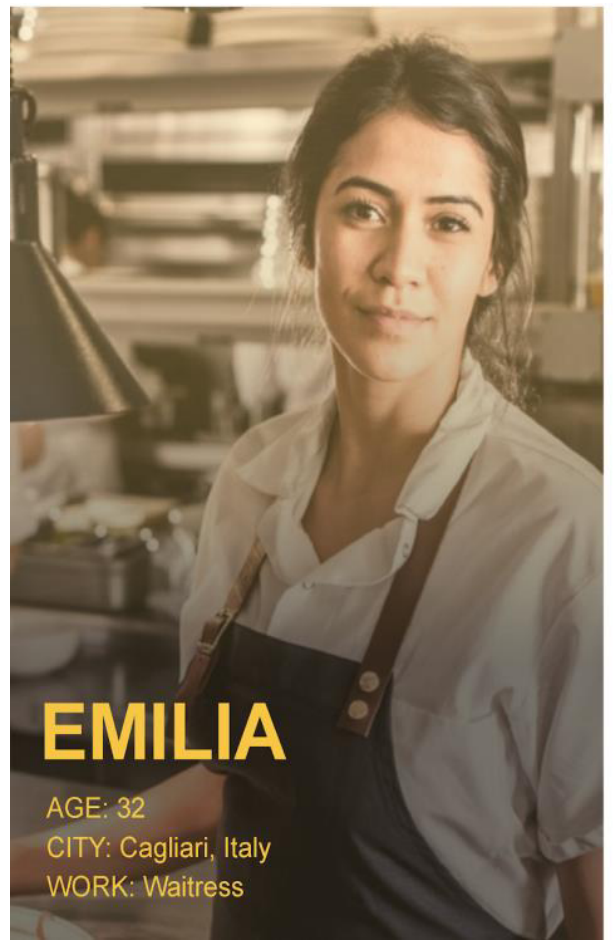

\section{DESCRIPTION}

Always passionate about good food, she began to approach the culinary world from a very young age. She has been working in a restaurant for 5 years as waitress.

She likes to travel to discover the typical products and the whole Italian territory. She is especially interested in knowing the history of the products and taking inspiration for new recipes that enhance the properties of food.

\section{NEEDS AND EXPECTATIONS}

She wants to be able to get in touch with the various Italian food cultures, in order to increase her knowledge even at a distance.

Figure 3. Example of personas from User research

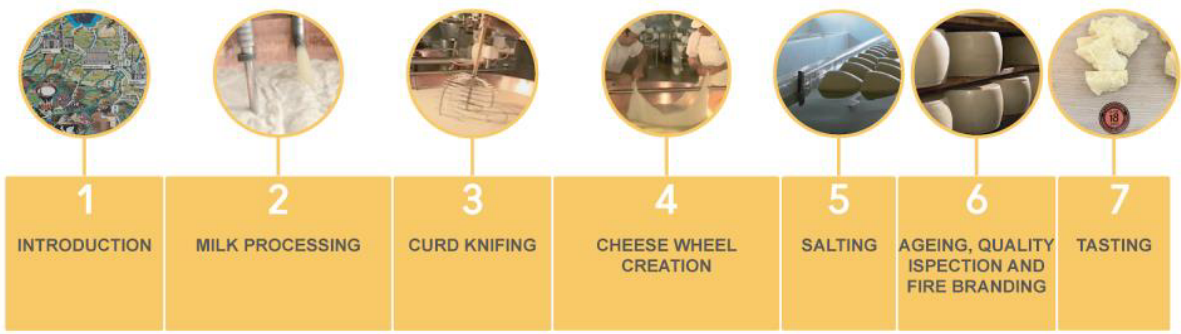

Figure 4. Storytelling for the Parmigiano Reggiano production process.

The third scene referred to the beating of cheese wheels, which takes place in the seasoning warehouse. It is an interactive scene since the user is invited to carry out a beating task on his own, exploiting VR devices. The user can use a particular gavel and beat a cheese wheel in specific points of the surface, looking at an expert. When the gavel hit the cheese wheel, the visitor hears the typical sounds, that vary depending on the specific point of the wheel.

The fourth scene is probably the most impressive one and referred to the cheese wheel branding. This phase takes place in the seasoning warehouse where the user is invited to pick up the marker and engrave the consortium stamp on the lateral side of the cheese wheel. In order to improve the realism of the scene, a flame animation was implemented and when the marker collides with the cheese surface, a small column of smoke rises from emulating the real effect. 
The last scene is about cheese tasting and aims to involve the consumer to finally buy the product. The avatar tour guide describes the tasty peculiarity and the aftertaste sensations that characterizes each cheese ageing (e.g. 12, 18, 24 and over 36 months). Every ageing is also described by the ingredients individuated as aftertaste to be combined with the tasting, to create the proper desire to taste. Figure 5 shows examples of the implemented scenes in the VT.

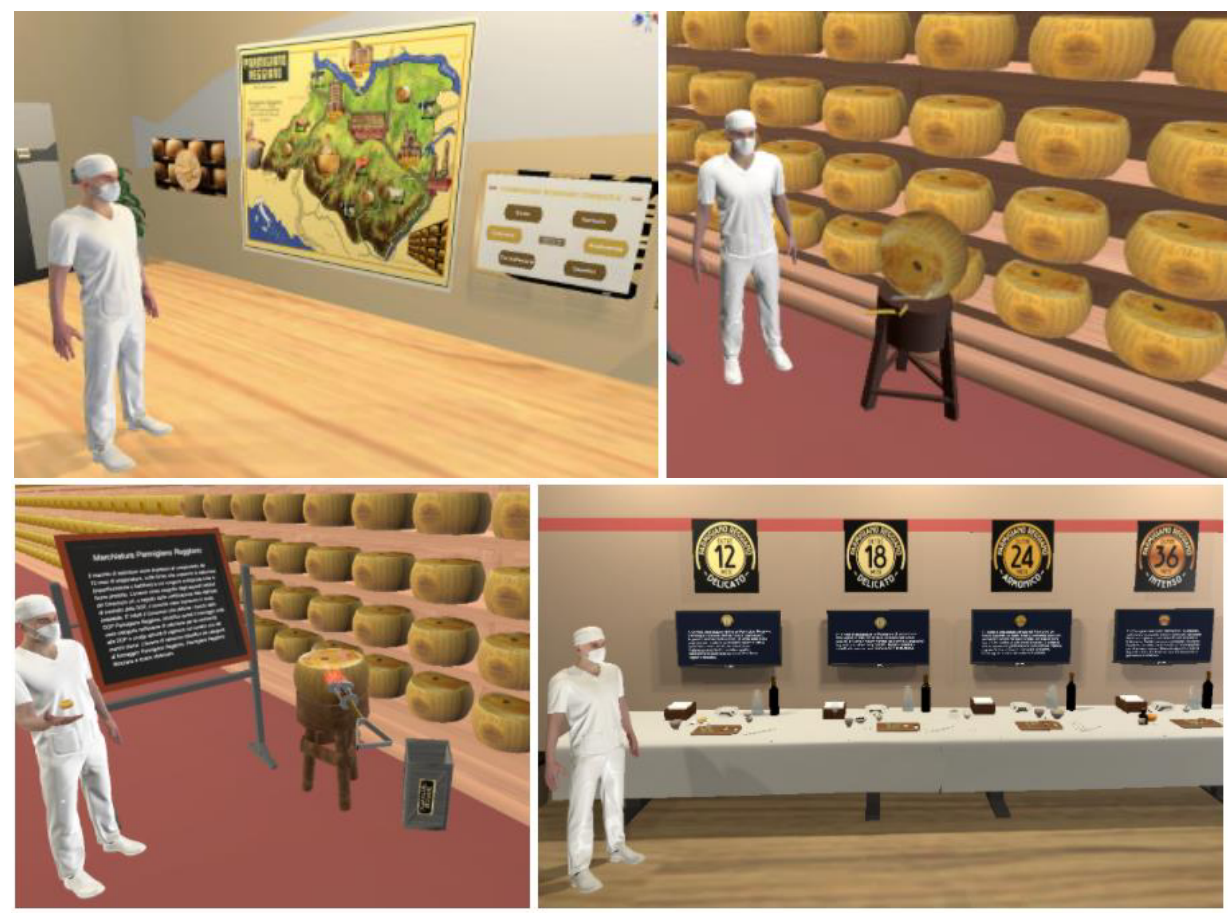

Figure 5. Examples of VT scenes: welcome virtual scenario (up-left), the beating PR scenario (upright), the fire branding virtual scenario (down-left), the virtual tasting (down-right).

\section{Results}

The proposed VT was qualitatively evaluated by a preliminary test carried out in Lab environment involving 8 users recruited from university employees. Users range from 20 to 40 years old, $75 \%$ male and $25 \%$ female. The sample of users is made of $50 \% \mathrm{VR}$ experts or middle-experts, and 50\% completely inexperienced. The VT lasted approximately 20 minutes for each user, excluding the calibration device phase before each session. A set of metrics was defined to assess the quality of the virtual experience as summed up in Figure 6. Each user was asked to judge the quality of the lived experience according to a 5-point Likert scale using the post-test questionnaire. Table 1 shows the collected results. Results were also presented by a bar graph in order to better show the main significant metrics, as reported in Table 1. A low average value for Sickness $(2,0)$ indicates a good quality of the virtual simulation and comfort of the overall experience. This is due to the high refresh rate and a high- quality rendering offered by the selected devices. The high score values obtained for Immersion level $(4,5)$ and 
Realism $(4,1)$ demonstrate the effectiveness of this type of simulation. Thanks to the high-quality rendering reconstruction, an effective life-like reproduction of the entire production process is achieved. Also, Level of interest $(4,4)$ and Engagement $(3,9)$ reported high scores, highlighting the good user involvement and the high emotional involvement of the users, demonstrating the potential success of the proposed marketing strategy. Moreover, the scenes' structure was settled up with an intuitive interface, as demonstrated by Ease to use score $(4,3)$. Although these final scores don't have statistical significance, they can provide useful information on the perception of the user's experience about the proposed VT.

Table 1. Users' test values from evaluation questionnaires.

$\begin{array}{lllllllll}\text { User } 1 & \text { User } 2 & \text { User } 3 & \text { User } 4 & \text { User } 5 & \text { User } 6 & \text { User } 7 & \text { User } 8 & \text { Aver. }\end{array}$

\begin{tabular}{llllllllll}
\hline Engagement & 4 & 5 & 3 & 5 & 4 & 4 & 4 & 2 & 3,9 \\
\hline Level of interest & 5 & 4 & 5 & 5 & 5 & 4 & 4 & 3 & 4,4 \\
\hline Ease to use & 4 & 4 & 5 & 5 & 4 & 5 & 3 & 4 & 4,3 \\
\hline Immersion level & 4 & 5 & 5 & 5 & 4 & 5 & 5 & 3 & 4,5 \\
\hline Realism & 3 & 4 & 5 & 5 & 4 & 4 & 5 & 3 & 4,1 \\
\hline Sickness & 2 & 1 & 2 & 4 & 2 & 1 & 1 & 3 & 2,0 \\
\hline
\end{tabular}

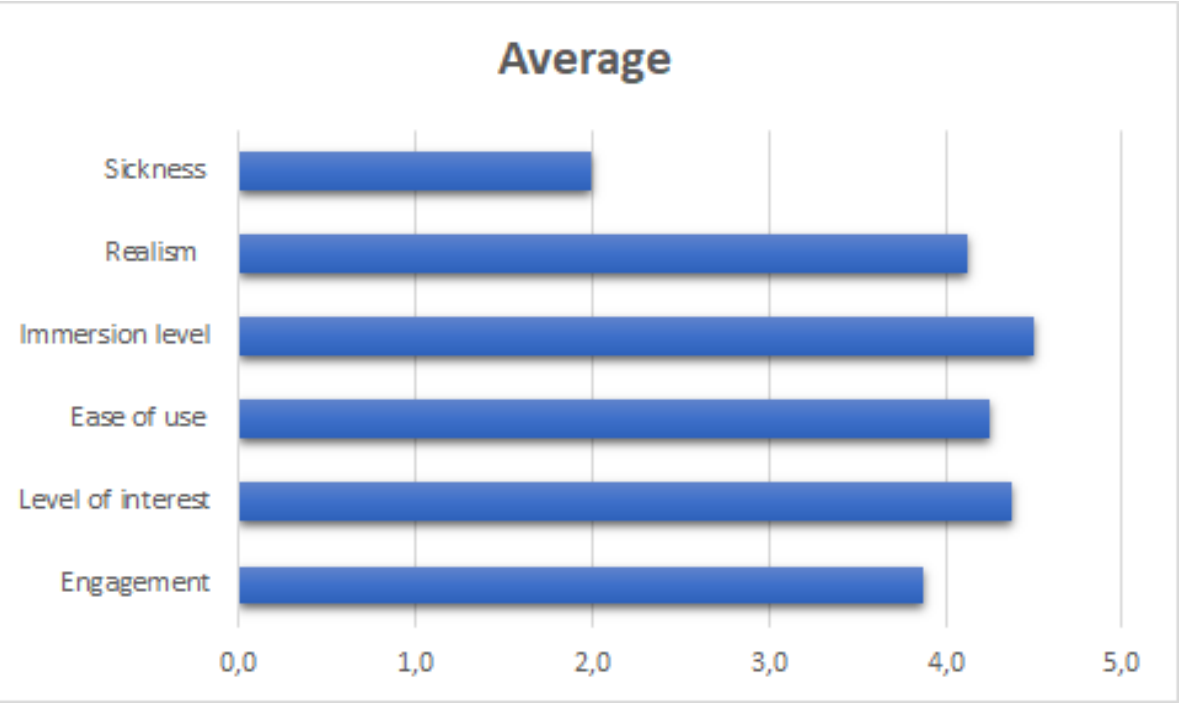

Figure 6. Average scores from qualitative users' assessment.

\section{Conclusion}

The study highlighted the strengths of the new digital technologies and their important role in the development of remote user experience. Indeed, VR tools could replace the 
static experience of e-commerce sites by offering the possibility to virtually visit a production site thanks to an interactive experience. Results obtained from preliminary tests showed a general positive evaluation of the VT: thanks to the transdisciplinary approach, users can live an immersive tour that simulates the user interaction, improving the user knowledge about the production process, and further augmenting what users usually live during the traditional visit. Moreover, the VT was able to overcome the geographical barriers, making a visit feasible also when it is not possible. This aspect assumes a particular importance in the recent Covid-19 scenario, when social distancing is affecting on-site visits and consequently sales. As a result, the remote experience by VTs can relaunch local companies promoting their products worldwide. Future works will focus on the comparison between the experience lived by the proposed VT and by the classical physical tour, using a larger statistical sample of users, in order to validate the effectiveness of this tool and the impact on sales intention. Moreover, feedback from users during and after testing will be investigated also by adopting wearable devices (e.g. heart-band, smartwatch) to collect physiological data to quantify the users emotional state, and extending the user sample. In addition, also intention to buy will be investigated.

\section{Acknowledgements}

The research was funded by the Unimore University Fund for Research as the interdisciplinary FAR2019 project entitled "New digital tools for remote customer experience: how to promote the Modenese agri-food typical products". Authors wish to acknowledge also the Parmigiano Reggiano Consortium for the precious collaboration.

\section{References}

[1] S. R. Ellis, What are virtual environments?, IEEE Comput. Graph. Appl., 1994, Vol. 14, no. 1, pp. 17-22.

[2] R. Manseur, Virtual reality in science and engineering education, Proceedings Frontiers in Education 35th Annual Conference, 2005, pp. F2E-8.

[3] R. Aggarwal et al., An evidence-based virtual reality training program for novice laparoscopic surgeons, Ann. Surg. , 2006, Vol. 244, No. 2, pp. 310-314.

[4] M. Peruzzini, F. Grandi, S. Cavallaro, and M. Pellicciari, Using virtual manufacturing to design human-centric factories: an industrial case, Int. J. Adv. Manuf. Technol., 2021, Vol. 115, pp. 873-7.

[5] A. Fineschi and A. Pozzebon, A 3D virtual tour of the Santa Maria della Scala Museum Complex in Siena, Italy, based on the use of Oculus Rift HMD, 2015 International Conference on 3D Imaging (IC3D), 2015, pp. 1-5.

[6] T. Griffin, J. Giberson, S. H. M. Lee, D. Guttentag, M. Kandaurova, K. Sergueeva and F. Dimanche, Virtual reality and implications for destination marketing, Travel and Tourism Research Association: Advancing Tourism Research Globally, 2017.

[7] S. Barnes, "Understanding virtual reality in marketing: Nature, implications and potential," Implic. Potential (November 3, 2016), 2016, http://dx.doi.org/10.2139/ssrn.2909100.

[8] H. Stuart, Virtual Reality Marketing: Using VR to Grow a Brand and Create Impact. Kogan Page Publishers, London, 2018.

[9] D. Streimikiene and E. Korneeva, Economic impacts of innovations in tourism marketing, Terra Econ., 2020, Vol. 18, No. 3, pp. 182-193.

[10] E. Baek, H. J. Choo, X. Wei, and S. Y. Yoon, Understanding the virtual tours of retail stores: how can store brand experience promote visit intentions?, International Journal of Retail \& Distribution Management, 2020, Vol. 48, No. 7, pp. 649-666.

[11] J. Hagberg, M. Sundstrom, and N. Egels-Zandén, The digitalization of retailing: an exploratory framework, International Journal of Retail \& Distribution Management, 2016, Vol. 44 No. 7, pp. 
694-712.

[12] R. Lohre, A. J. Bois, G. S. Athwal, and D. P. Goel, Improved complex skill acquisition by immersive virtual reality training: a randomized controlled trial, JBJS, 2020, Vol. 102, No. 6, p. e26.

[13] A. Rizzo et al., Development of a VR therapy application for Iraq war military personnel with PTSD, Stud. Health Technol. Inform., 2005, Vol. 111, pp. 407-413.

[14] L. Montagna, Realtà virtuale e realtà aumentata: nuovi media per nuovi scenari di business. Hoepli Editore, Milano, 2018.

[15] D. Fontana, Realtà Virtuale e Aumentata: scenari applicativi per il marketing, Hoepli Editore, Milano, 2019.

[16] C. Yildirim, Cybersickness during VR gaming undermines game enjoyment: A mediation model, Displays, 2019, Vol. 59, pp. 35-43.

[17] M. Gödde, F. Gabler, D. Siegmund, and A. Braun, Cinematic narration in VR-Rethinking Film conventions for 360 degrees, International Conference on Virtual, Augmented and Mixed Reality, 2018, pp. 184-201.

[18] Z. Merchant, E. T. Goetz, L. Cifuentes, W. Keeney-Kennicutt, and T. J. Davis, Effectiveness of virtual reality-based instruction on students' learning outcomes in K-12 and higher education: A meta-analysis, Comput. Educ., 2014, Vol. 70, pp. 29-40.

[19] H.-M. Chiao, Y.-L. Chen, and W.-H. Huang, Examining the usability of an online virtual tourguiding platform for cultural tourism education, J. Hosp. Leis. Sport Tour. Educ., 2018, Vol. 23, pp. $29-38$.

[20] M. C. tom Dieck, T. H. Jung, and D. tom Dieck, Enhancing art gallery visitors' learning experience using wearable augmented reality: generic learning outcomes perspective, Curr. Issues Tour. , 2018, Vol. 21, no. 17, pp. 2014-2034.

[21] H. Van Kerrebroeck, M. Brengman, and K. Willems, When brands come to life: experimental research on the vividness effect of Virtual Reality in transformational marketing communications, Virtual Real., 2017, Vol. 21, No. 4, pp. 177-191.

[22] G. Zeng, X. Cao, Z. Lin, and S. H. Xiao, When online reviews meet virtual reality: Effects on consumer hotel booking, Ann. Tour. Res. , 2020, Vol. 81, p. 102860.

[23] J. C. Henderson, Food tourism reviewed, British Food Journal, 2009, Vol. 111, 317-326.

[24] C. Hartmann, and M. Siegrist, Virtual reality and immersive approaches to contextual food testing. Context: The Effects of Environment on Product Design and Evaluation, 2019, pp. 323-338.

[25] R. K. Napolitano, G. Scherer, and B. Glisic, Virtual tours and informational modeling for conservation of cultural heritage sites, J. Cult. Herit., 2018, Vol. 29, pp. 123-129.

[26] O. B. P. Mah et al., Generating a virtual tour for the preservation of the (in) tangible cultural heritage of Tampines Chinese Temple in Singapore, J. Cult. Herit., 2019, Vol. 39, pp. 202-211.

[27] D. A. L. Carvajal, M. M. Morita, and G. M. Bilmes, Virtual museums. Captured reality and 3D modeling, J. Cult. Herit., 2020, Vol. 45, pp. 234-239.

[28] A. Marasco, P. Buonincontri, M. van Niekerk, M. Orlowski, and F. Okumus, Exploring the role of next-generation virtual technologies in destination marketing, J. Destin. Mark. Manag., 2018, Vol. 9, pp. 138-148.

[29] Y.-C. Huang, S. J. Backman, K. F. Backman, and D. Moore, Exploring user acceptance of 3D virtual worlds in travel and tourism marketing, Tour. Manag., 2013, Vol. 36, pp. 490-501.

[30] D.-I. D. Han, J. Weber, M. Bastiaansen, O. Mitas, and X. Lub, Virtual and augmented reality technologies to enhance the visitor experience in cultural tourism, M. C. tom Dieck and. T. Jung (eds.) Augmented reality and virtual reality, Springer Nature Switzerland, 2019, pp. 113-128.

[31] J. A. Bennett and C. P. Saunders, A virtual tour of the cell: Impact of virtual reality on student learning and engagement in the STEM classroom, J. Microbiol. Biol. Educ., 2019, 26;20(2):20.2.37.

[32] O. B. P. Mah, ... and C. C. Feng, Generating a virtual tour for the preservation of the (in)tangible cultural heritage of Tampines Chinese Temple in Singapore. Journal of Cultural Heritage, 2019, Vol. 39, pp. 202-211.

[33] L. Argyriou, D. Economou and V. Bouki, Design methodology for 360 immersive video applications: the case study of a cultural heritage virtual tour, Pers. Ubiquitous Comput., 2020, pp. $1-17$.

[34] J. Pruitt and T. Adlin, The persona lifecycle: keeping people in mind throughout product design. Elsevier, San Francisco, 2006.

[35] J. Pulizzi, The rise of storytelling as the new marketing, Publ. Res. Q., 2012, Vol. 28, No. 2, pp. 116 123. 